\title{
TRANSFORMAÇÕES NAS POLÍTICAS DE EDUCAÇÃO DE JOVENS E ADULTOS NO BRASIL NO INÍCIO DO TERCEIRO MILÊNIO: UMA ANÁLISE DAS AGENDAS NACIONAL E INTERNACIONAL
}

\author{
Maria Clara Di Pierro* \\ Sérgio Haddad ${ }^{* *}$
}

\begin{abstract}
RESUMO: $\mathrm{O}$ ensaio analisa as transformaçóes nas políticas de educação de jovens e adultos (EJA) no Brasil do início do século XXI, face aos direitos reconhecidos na legislação nacional e aos compromissos assumidos em fóruns internacionais (alguns dos quais estão sendo revistos em 2015). Com base em revisão da literatura e análise de políticas, o artigo destaca a ampliação do reconhecimento jurídico de direitos dos jovens e adultos à formação e a institucionalização da modalidade nas políticas de educação básica. O resultado das políticas de EJA, entretanto, frustrou as expectativas e ficou distante dos direitos proclamados e das metas compromissadas, evidenciando que a cultura do direito à educação ao longo da vida não está ainda enraizada na sociedade e nos governos.
\end{abstract}

Palavras-chave: Educação de jovens e adultos. Políticas educacionais.

\footnotetext{
* Universidade de São Paulo, Faculdade de Educação, São Paulo, SP., Brasil. E-mail de contato: mcpierro@usp.br.

** Ação Educativa, São Paulo, SP., Brasil. E-mail de contato: sergiohaddad@terra.com. br.
} 


\title{
Transformations in Youth and Adult Education policies in Brazil at the beginning of the third millennium: an analysis of national and international agendas
}

\begin{abstract}
This essay analyzes the transformations in Youth and Adult Education policies in Brazil at the beginning of the 21 st century, in view of rights that are recognized in the national legislation and the commitments that have been undertaken at international forums, (some of which are being revised in 2015). Based on literature review and policy analysis, the article highlights the expansion of the legal recognition of the rights of youth and adults to education and the institutionalization of this modality in basic education policies. The results of youth and adult education policies, however, have frustrated expectations and have remained distant from the proclaimed rights and goals to which we have committed ourselves, making it evident that the culture of lifelong education has not yet been rooted in society and in governments.
\end{abstract}

Keywords: Youth and adult education. Education policies.

\section{INTRODUÇÃO}

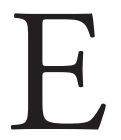

xpectativas positivas nos planos nacional e internacional cercaram a educação de jovens e adultos (EJA) na transição para o terceiro milênio: foram aprovadas declaraçóes, acordos, leis e documentos sobre o direito humano à educação ao longo da vida que cobraram dos governos políticas para sua efetivação.

É bem verdade que os avanços decorrentes do reconhecimento do direito dos jovens e adultos à formação foram limitados pelo esvaziamento das políticas de bem-estar social construídas no período pós-guerras, à medida que as orientaçóes neoliberais se tornaram hegemônicas no final do século XX.

No Brasil, o reconhecimento do direito dos jovens e adultos à educação foi consequência do processo de democratização na transição 
dos anos 1980 e 1990, após 20 anos de ditadura militar, que produziu em 1988 uma Constituição avançada na garantia dos direitos sociais. Como em outras partes do mundo, a realização desses direitos foi limitada pelas políticas de ajuste macroeconômico e redefiniçấo do papel do Estado.

Já no plano internacional, os acordos estabelecidos pela maioria dos países, inclusive o Brasil, aprofundavam os compromissos firmados na Declaração Universal dos Direitos Humanos de 1948, que estabeleceu as condições básicas para uma vida digna.

No Brasil, a mobilização da sociedade civil foi propulsora da conquista de direitos, como o reconhecimento dos jovens e adultos dentre os sujeitos do direito humano à educação, antes restrito às crianças e adolescentes. No plano internacional não foi diferente: encabeçadas pela Organização das Naçóes Unidas (ONU), as diversas conferências, realizadas a partir dos anos 1990, sobre direitos sociais contaram com a participação ativa da sociedade civil para o reconhecimento de direitos pelos seus governos.

Um dos resultados dramáticos, da combinação entre um mundo mergulhado no neoliberalismo e o avanço do direito à educação, tem sido a frustaçáo diante da constatação de que os esforços por colocar a EJA na agenda dos governos náo resultaram em avanços significativos. Tanto no Brasil, quanto no mundo, o número de analfabetos jovens e adultos diminui lentamente e os avanços na escolaridade desse grupo são tímidos. $\mathrm{O}$ dilema talvez resida justamente na consequência maior das políticas neoliberais: o aprofundamento das desigualdades sociais, cenário em que os potenciais educandos da EJA não poderiam mesmo ver seus direitos realizados.

No presente artigo, realizamos uma análise que se inscreve na vertente teórica da sociologia política da educação (AFONSO, 2001; TORRES, 1996; 2013), abordagem que adota uma perspectiva crítica do poder (nas organizaçóes complexas e no Estado), que procura realizar uma análise integrada dos determinantes (econômicos, sociais, políticos e culturais) de formação das políticas educativas, considerando o contexto de transnacionalização do capitalismo e globalização cultural, bem como, a redefiniçãoo do papel do Estado na regulação das políticas públicas (BARROSO, 2005), e que comporta ainda o exame das con- 
dições e perspectivas de transformação de tais políticas pela cidadania democrática.

\section{A EJA NA AGENDA INTERNACIONAL DA EDUCAÇÃO}

A agenda internacional vem gradativamente ganhando relevância nos últimos anos no Brasil, não só pela intensificação do processo de globalização observado em todos os âmbitos da vida, como pelo papel que o país passou a desempenhar nos cenários regional e global. Apesar disso, o debate interno sobre essa agenda ainda é pequeno, em especial, no campo da educação e da EJA.

Mesmo não tendo carater impositivo, acordos internacionais assinados pelos governos nacionais podem se constituir em instrumentos para que a sociedade civil - em cada país ou nas redes globais - exerça pressão para a garantia de direitos, mudança de leis e comportamentos, acesso a informações ou reivindicação de políticas públicas. As metas internacionais associadas a esses acordos direcionam a cooperação internacional bilateral e multilateral, estimulando governos nacionais a perseguir os compromissos para acessar tais recursos, responder às pressões ou evitar sançóes externas. Quase sempre os principais motores da mudança são domésticos, resultados da pressão das sociedades nacionais, mas as iniciativas internacionais são fatores de segunda ordem que podem influenciar as decisôes políticas. Declaraçôes globais podem suscitar declaraçóes nacionais, regionais e locais. Por outro lado, a comparação com outros países pode fornecer argumentos para a advocacia por direitos e o exercício da pressão política.

As referências internacionais oriundas de acordos e metas para a temática da EJA, na entrada do terceiro milênio, estavam demarcadas por três agendas principais: os Objetivos de Desenvolvimento do Milênio (ODMs), acordo assinado em 2000; as metas de Educação Para Todos (EPT), criadas em 1990 em Jomtien (Tailândia) e renovadas em 2000 em Dakar (Senegal); e a Declaração de Hamburgo (Alemanha) e Agenda para o Futuro subscritas em 1997 na V Conferência Internacional de Educação de Adultos (Confintea). O ano de 2015 é referência para os dois primeiros acordos, prazo em que as metas estabelecidas vencem. 
No caso da Declaração de Hamburgo, uma nova Confintea ocorreu em 2009 em Belém do Pará, reafirmando compromissos para a EJA e estabelecendo novas estratégias para o seu desenvolvimento.

\subsection{OS OBJETIVOS DE DESENVOLVIMENTO DO MILÊNIO}

Os oito ODMs foram acordados em 2000 por 189 países com o intuito de compatibilizar, em uma agenda, única os compromissos com o desenvolvimento social assumidos em diferentes conferências promovidas pelo sistema da ONU, ao longo dos anos 1990.

A Conferência das Naçóes Unidas para o Desenvolvimento Sustentável (2012), conhecida como Rio+20, apesar dos escassos avanços no estabelecimento de compromissos práticos, serviu como ponto de partida para a elaboração dos Objetivos de Desenvolvimento Sustentável (ODSs) que substituirão os ODMs a partir de 2015.

As principais críticas dirigidas aos ODMs giraram em torno do fato das metas serem pouco ou nada desafiadoras para os países de renda média e alta, focando os países mais pobres, que tiveram que assumir toda responsabilidade por atingi-las, já que os esforços da cooperação internacional foram mínimos. Praticamente não houve metas para os países desenvolvidos, nem definição sobre suas responsabilidades. $\mathrm{O}$ Brasil, sendo um país de renda média, atingiu antes do prazo as metas de redução da pobreza e fome, e avançou em relação aos demais indicadores.

Os ODMs não fixaram uma meta específica para EJA. O tema da educação foi tratado no Objetivo 2 - Alcançar educação primária universal. Em seu último relatório para o Brasil, de 2014, o Programa das Naçóes Unidas para o Desenvolvimento (Pnud) avaliou positivamente os avanços das políticas brasileiras de universalização da educação primária e ampliação de oportunidades educacionais para a juventude. No entanto, o Relatório Global sobre os ODMs de 2014 admitiu que o número de analfabetos entre jovens e adultos no mundo permaneceu alto, apesar da pequena melhora ao longo dos anos: 
Ao longo das últimas duas décadas, o mundo observou um progresso significativo na taxa de alfabetização de jovens e adultos e, simultaneamente, uma diminuiçáo na lacuna entre o índice de mulheres e homens alfabetizados. A taxa de alfabetismo da população jovem entre 15-24 anos aumentou globalmente de 83\%, em 1990, para 89\% em 2012. A taxa de alfabetizaçáo de adultos, para a população com 15 anos ou mais, aumentou de $76 \%$ para $84 \%$. Ainda assim, havia 781 milhóes de adultos e 126 milhóes de jovens ao redor do mundo sem habilidades básicas de escrita e leitura em 2012, com as mulheres somando mais de 60\% de ambas as populaçóes jovem e adulta. (ONU, 2014, p. 16)

\subsection{A INICIATIVA DE EDUCAÇÃO PARA TODOS}

Diante dos escassos progressos realizados na década de 1990, o compromisso com a Educação para Todos (EPT) foi reafirmado pelos 164 governos reunidos em Dakar em 2000, na Cúpula Mundial de Educação. A meta de oferecer a todas as crianças, jovens e adultos uma educaçáo que satisfaça suas necessidades básicas de aprendizagem foi postergada para 2015. Essa meta foi desdobrada em seis objetivos relacionados à ampliação do acesso à educação na primeira infância, ao ensino primário universal, à educação de qualidade com equidade de gênero, sendo dois deles diretamente relacionados à EJA:

1. Assegurar que as necessidades de aprendizagem de todos os jovense adultos sejam alcançadas através de acesso equitativo a programas apropriados de aprendizagem e competências para a vida.

2. Alcançar $50 \%$ de melhora nos niveis de educação de adultos até 2015, especialmente para as mulheres, e acesso equitativo à educação básica e continuada para adultos.

O Brasil está entre os 53 países que ainda não atingiram, e nem estáo perto de atingir, os objetivos de EPT até 2015, apesar dos 
avanços registrados na frequência ao ensino fundamental e na ampliação do acesso ao ensino superior.

O 11․ Relatório de Monitoramento Global de EPT, apresentado pela Unesco em 2015, assinala a existência em todo o mundo de 781 milhôes de adultos analfabetos (uma reduçáo de apenas 1\% desde 2000), sendo que $72 \%$ deles estão em 10 países. (UNESCO, 2015a) O Brasil ocupa a $8^{a}$ posição entre as nações com maior número de analfabetos adultos, e a Unesco avalia que o país terá dificuldades para alcançar a meta de melhorar em $50 \%$ os níveis de alfabetização de adultos até 2015. De fato, na Pesquisa Nacional por Amostra de Domicílios (Pnad) de 2012, a taxa de analfabetismo de pessoas de 15 anos ou mais no país foi de 8,7\%, correspondendo a 13,2 milhóes de analfabetos; em 2000, o índice de analfabetismo era de $13,6 \%$, quando o Censo contabilizou 16,3 milhões de analfabetos.

\subsection{AS CONFERÊNCIAS INTERNACIONAIS DE EDUCAÇÃO DE ADULTOS}

Realizando-se periodicamente desde 1949, as Confinteas firmaram-se como o espaço internacional de orientação para as políticas de EJA. Sendo classificadas pela ONU como conferências de nível 2, seu impacto e relevância para os governos é menor que os ODMs ou a iniciativa de EPT.

A Confintea V, realizada em 1997, teve força convocatória e produziu a Declaração de Hamburgo e Agenda para o Futuro (UNESCO, 1999), documentos que exerceram influência intelectual e política sobre a EJA, renovando o conceito que delimita o campo e impulsionando a difusão da perspectiva da educação e aprendizagem ao longo da vida.

Após 12 anos, a Confintea VI, que o Brasil sediou, reafirmou esses conceitos, aprovou o Quadro de Ação de Belém e buscou convergências com outras agendas internacionais de alfabetização, educação e desenvolvimento. $\mathrm{O}$ evento oficial foi precedido por um vibrante Fórum Internacional da Sociedade Civil. (HADDAD, 2009) 
Embora a Confintea V tenha tido uma participação recorde e os avanços tenham sido preservados, o evento frustrou os brasileiros, que esperavam que o esforço realizado para sediá-la pudesse ser capitalizado para reposicionar a EJA na agenda nacional de política educativa, o que não ocorreu. A ausência do Presidente da República, Luiz Inácio Lula da Silva, [N.E.: 35․ Presidente da República do Brasil, período de 2003 a 2011], e a rápida passagem do Ministro da Educação, Fernando Haddad, pela Conferência foram percebidas como um desprestígio do tema, e o simbolismo de sua realização na Amazônia foi negativamente compensado pelo escasso impacto midiático decorrente do isolamento da cidade de Belém em relação aos grandes centros.

\subsection{PERSPECTIVAS GLOBAIS PÓS-2015}

Os contornos que os compromissos globais relativos ao desenvolvimento social e à educação assumirão a partir de 2015 ainda estavam se delineando, quando da escrita deste artigo, em meio a negociaçóes e disputas sobre as metas e as estratégias para alcançá-las.

Os Objetivos de Desenvolvimento Sustentável (ODSs) compreendem três dimensões - transformação econômica, justiça social e proteçáo ambiental -, e devem ser adotados na Assembleia Geral da ONU de Nova Iorque, em setembro de 2015. A última proposta, que veio a público no início de 2015, apresentava 17 objetivos a serem alcançados até 2030, sendo um deles o de Assegurar educaçáo equitativa e inclusiva de qualidade e promover oportunidades de aprendizagem ao longo da vida para todos. Esse objetivo se desdobra em sete metas, das quais três remetem à EJA: 1) garantir acesso igualitário para todas as mulheres e homens à educação pós-secundária vocacional e técnica de qualidade, incluindo o ensino superior, a preços acessíveis; 2) ampliar a proporção de jovens e adultos com habilidades relevantes, incluindo aquelas técnicas e vocacionais para empregabilidade, trabalho decente e empreendedorismo; 3) garantir que todos os jovens e uma proporção dos adultos, tanto homens quanto mulheres, alcancem letramento e numeracia.

Essas formulações têm sido criticadas por movimentos sociais e organizaçóes civis por representarem desafios tímidos, adotarem uma 
perspectiva privatista e se inscreverem em uma visão instrumental da EJA, subordinando-a às exigências do mercado de trabalho em detrimento de uma concepção de educação como direito humano.

A renovação dos compromissos em prol da EPT e das estratégias dessa iniciativa, por sua vez, ocorreu em Incheon, Coreia do Sul, de 19 a 22 de maio de 2015. Os princípios e a agenda preliminar foram negociados em um encontro realizado em Muscat (Omã) em 2014. A Declaração de Incheon, assinada por mais de cem países durante o Fórum Mundial de Educação, em maio deste ano, afirma que

Nós [Estados] também nos comprometemos a assegurar que todos os jovens e adultos, especialmente meninas e mulheres, alcancem níveis relevantes de proficiência em letramento e matemática e adquiram habilidades para a vida, e que sejam providos com aprendizado de adultos, educaçáo e oportunidades de formação. (UNESCO, 2015b, p. 3) ${ }^{2}$

Embora as formulaçóes de EPT sejam melhores que aquelas previstas nos ODSs, elas também não propóem a universalidade do direito dos adultos à alfabetização e à educação ao longo da vida, nem recomendam sua gratuidade.

Já os compromissos firmados na Confintea VI (UNESCO, 2010b) perderam relevância no plano internacional. O monitoramento dos acordos firmados ficou a cargo do Instituto da Unesco para a Educação ao Longo da Vida, em Hamburgo, que lançou, em 2009 e 2013, Relatórios Globais sobre a Aprendizagem e Educação de Adultos. (UNESCO, 2010a; 2014) A produção desses relatórios tem enfrentado sérias limitaçóes pela falta de informaçóes nacionais, o que compromete sua relevância e impacto, indicando também descompromisso de grande parte dos países com o monitoramento e a melhoria das políticas de EJA. A conferência de meio termo para avaliar os avanços dos compromissos firmados, inicialmente prevista para 2015, foi postergada para 2016. 


\section{A EJA NA AGENDA NACIONAL DE POLÍTICAS EDUCACIONAIS}

\subsection{EXPECTATIVAS E FRUSTRAÇÕES DA PRIMEIRA DÉCADA DO TERCEIRO MILÊNIO}

No âmbito nacional, a EJA se manteve na agenda de políticas educacionais no início do terceiro milênio por diferentes razóes. De um lado, a oferta pública de oportunidades de alfabetização, elevação de escolaridade e formação para o trabalho tornou-se uma imposição legal pela Constituição de 1988 e a Lei de Diretrizes e Bases da Educação Nacional (LDBEN) de 1996, ao reconhecerem o direito público subjetivo dos jovens, adultos e idosos ao estudo. A garantia desse direito é responsabilidade compartilhada pelos Estados e Municípios, sob a coordenação e com a colaboração supletiva da União, que ao longo da história republicana exerceu papel indutor nesse campo educativo. (BEISIEGEL, 2003) Tais definiçóes foram reafirmadas em 2000 pelo Parecer 11 da Câmara de Educação Básica do Conselho Nacional de Educação que conferiu maior legitimidade às demandas por oportunidades de educação ao longo da vida. (CURY, 2000) Essas referências jurídicas instruíram a Lei n. 10.172 do I Plano Nacional de Educação 2001-2010, que fixou metas ousadas, porém não detalhou meios para atingi-las e nem previu mecanismos de responsabilização no caso do descumprimento, o que contribuiu para que o Plano fosse pouco efetivo.

No âmbito das políticas governamentais, a EJA fora postergada na agenda dos anos 1990 que priorizou a universalização do acesso ao ensino obrigatório na infância e adolescência, enfrentando restriçóes financeiras que vigoraram até 2006, devido à sua exclusão dos cômputos do Fundo de Desenvolvimento do Ensino Fundamental. (DI PIERRO, 2005) A janela de oportunidade para a mudança nas orientaçóes das políticas educacionais se abriu com a alternância no governo da União em 2003, quando a coalizão liderada pelo Partido dos Trabalhadores (PT) foi eleita em substituição ao Partido da Social Democracia Brasileira (PSDB).

No primeiro momento, a alfabetização de jovens e adultos foi reconhecida como dívida social e prioridade nacional, compondo o rol 
de medidas de combate à pobreza agrupadas sob o título Fome Zero, cujo carro-chefe foi o programa de transferência de renda Bolsa-Família, e que previu também estratégias de participação popular. ${ }^{3}$ Nesse contexto, o MEC lançou em 2003 o Programa Brasil Alfabetizado (PBA) e, para gerenciá-lo de modo descentralizado em parceria com os governos subnacionais, criou uma Secretaria Extraordinária e uma Comissão Nacional de Alfabetização. Na contramão do pensamento contemporâneo sobre as necessidades e estratégias de letramento das pessoas jovens e adultas, o PBA foi desenhado como ação setorial, nos moldes das campanhas de alfabetização de massa do passado, com curta duração e baixo custo, estruturando-se em paralelo aos sistemas de ensino, improvisando alfabetizadores que recebem modesta ajuda de custo, escassa orientação e supervisão, e são responsáveis por recrutar os candidatos a compor as turmas. (CATELLI JR., 2014)

As demais tarefas de governança da EJA foram mantidas em uma Coordenação Geral na Secretaria de Educação Básica do MEC, e suas principais ações foram a ampliação da abrangência do apoio técnico e financeiro aos Estados e Municípios, rebatizada como Fazendo Escola, e a publicação de materiais para a formação de educadores, ao passo que o Instituto Nacional de Estudos e Pesquisas Educacionais (Inep) suspendia temporariamente a realização do Exame Nacional de Certificação de Competências de Jovens e Adultos (Encceja) para reavaliação de sua pertinência.

A substituição de ministros em 2004 ensejou um rearranjo interno no Ministério da Educação (MEC) ficando as ações de alfabetização e EJA reunidas em uma única Diretoria, no interior de uma secretaria dedicada às políticas de equidade dirigidas a grupos desfavorecidos no acesso à educação, como os povos indígenas, as populações rurais e comunidades quilombolas: a Secretaria de Educação Continuada, Alfabetização e Diversidade (Secad). A abrangência da Comissão Nacional foi ampliada, passando a compreender não só a alfabetização, mas toda EJA, e intensificou-se a interlocução da Secad com os Fóruns de $\mathrm{EJA}^{4}$, que passaram a receber apoio para manter um portal na internet e realizar encontros nacionais.

Nem todas as iniciativas federais voltadas à formação das pessoas jovens e adultas, porém, ficaram sob a coordenação desse nú- 
cleo: o Programa Nacional de Educação na Reforma Agrária (Pronera) continuou a ser conduzido pelo Instituto Nacional de Colonização e Reforma Agrária (Incra); constituída em 2005, a Secretaria Nacional de Juventude (SNJ) criou, em caráter experimental, o Programa Nacional de Inclusão de Jovens (Projovem Urbano), destinado à conclusão do Ensino Fundamental por jovens de baixa renda e precária inserção no mundo do trabalho, assumindo sua gestão até 2011, quando foi transferido para o MEC. A Secretaria de Educação Profissional e Tecnológica (Setec) do MEC, por sua vez, deu início em 2006 ao Programa Nacional de Integração da Educação Básica com a Educação Profissional na Modalidade de Educação de Jovens e Adultos (Proeja), que oferece cursos integrados de elevação de escolaridade (fundamental ou média) e formação profissional (inicial ou técnica) na rede federal de educação profissional e tecnológica. ${ }^{5}$

A EJA recebeu um novo impulso no segundo mandato do Presidente Lula quando foi incluída, embora em posição secundária em relação às demais etapas e modalidades, nas políticas estruturantes do sistema de educaçáo básica, que passaram a ser organizadas em torno ao Plano de Desenvolvimento da Educação (PDE). Dentre as 28 diretrizes do Compromisso Todos pela Educação, pelo qual os Estados e Municípios aderem ao PDE, consta apenas a manutenção de um programa de alfabetização de jovens e adultos, trato este que sequer é monitorado. Os estudantes da EJA não foram incluídos nos sistemas de aferição de desempenho instituídos pelo Inep para a composição do Índice de Desenvolvimento da Educação Básica (Ideb), fazendo com que os resultados de aprendizagem na modalidade estejam fora do campo de atenção dos gestores e da opiniáo pública. O Inep, porém, transpôs as resistências à centralização da certificaçấo, via exames, e voltou a realizar o Encceja em 2005 e, a partir de 2009, inseriu a certificação dos jovens e adultos entre as múltiplas funçóes desempenhadas pelo Exame Nacional do Ensino Médio (Enem). (CATELLI JR.; SERRAO, 2014)

A inscrição da EJA no Fundo de Desenvolvimento e Manutenção da Educação Básica e de Valorização dos Profissionais da Educação (Fundeb), com vigência de 2007 a 2020, realizou-se de forma progressiva e em condiçóes desfavoráveis, pois o fator de ponderação atribuído às matrículas efetuadas nos cursos presenciais da modalidade 
é o menor de todas as demais etapas e modalidades, existindo um teto de gasto que não pode exceder 15\% do total. Ainda assim, os recursos disponibilizados são maiores que aqueles com os quais a modalidade contava até então. (DI PIERRO, 2014)

Nos anos subsequentes, as matrículas presenciais da EJA passaram a ser consideradas também nos programas federais de alimentação e transporte escolar, do livro didático e descentralização de recursos para as escolas, melhorando substancialmente as condições de oferta, de ensino-aprendizagem e de permanência dos estudantes na escola.

A eficácia dessa política foi limitada pela dispersão dos programas e condicionada pela maior ou menor efetividade dos mecanismos de redistribuição entre as esferas de governo, uma vez que a oferta de EJA é desconcentrada nos 5.500 municípios das 27 unidades da Federação, variando segundo a capacidade financeira e administrativa de cada unidade (que difere sobremaneira) e as prioridades da política educacional local. Na tentativa de induzir a coordenação estadual das açóes, a Secadi propôs em 2008 que os Estados liderassem Agendas Territoriais de EJA, delineadas como processos de diagnóstico e planejamento pluri-institucionais. Salvo rara exceção, o intento foi malsucedido, e essa estratégia abandonada.

Malgrado as dificuldades enfrentadas na implementação das políticas públicas, o arcabouço legal relativo aos direitos educativos (e as responsabilidades estatal em assegurá-los) continuou avançando. Em 2009, a Emenda Constitucional n. 59 modificou a redação do Artigo n. 208 da Constituição para tornar obrigatória a Educação Básica desde a Pré-Escola até o Ensino Médio, "[...] assegurada inclusive sua oferta gratuita para todos os que a ela náo tiveram acesso na idade própria [...]", estendendo também aos educandos o acesso universal ao material didático escolar, transporte, alimentação e assistência à saúde. Ampliou-se, assim, o direito dos jovens e adultos ao Ensino Médio e aos programas suplementares a ele associados, obrigando compatibilizar a legislação infraconstitucional a essas determinaçóes, o que foi realizado pela Lei n. 12.796/2013, que modificou a LDBEN.

Por fim, em 2010, os Ministérios da Educação e da Justiça, assistidos pelos Conselhos Nacionais de Educação e de Política Criminal e 
Penitenciária, lograram acordo em torno das Diretrizes Nacionais para a Oferta de EJA em Situação de Privação de Liberdade nos Estabelecimentos Penais, que seriam reforçadas no ano seguinte, quando o Congresso modificou a Lei de Execução Penal, admitindo a remiçấo de pena pelo estudo. Esse quadro normativo repercutiu na política federal em fins de 2011, quando a Presidenta Dilma Rousseff instituiu o Plano Estratégico de Educação no âmbito do Sistema Prisional (Peesp), assegurando assistência da União aos Estados para seu alinhamento às novas Diretrizes.

A expectativa gerada por esse conjunto de normas, medidas e programas era a expansão e diversificação da oferta de oportunidades de aprendizagem dos jovens e adultos, com reflexos positivos nos índices de analfabetismo e escolarização da população, convergindo para as metas fixadas nos compromissos internacionais e planos nacionais. Tais expectativas foram frustradas quando os indicadores educacionais constataram o lento progresso nos índices de alfabetização e escolaridade dos brasileiros, e declínio constante das matrículas a partir de 2007, resultados que colocaram as políticas de EJA na berlinda.

As taxas de alfabetização da população brasileira com 15 anos ou mais avançaram apenas três pontos percentuais entre 2004 a 2013 , recuando de $88,5 \%$ para $91,5 \%$; esse modesto progresso deve-se principalmente à expansão do acesso à escola nas novas geraçôes. A estagnação das taxas de analfabetismo absoluto registradas pelas Pnads nos últimos anos tem sido atribuída a mudanças na estrutura etária (com ampliação da longevidade) combinada à dificuldade de os programas de alfabetização alcançarem os idosos. Nas pesquisas em que o grupo com idade mais avançada é expurgado, como no Indicador Nacional de Alfabetismo, aplicado à população de 15 a 65 anos, os progressos parecem mais significativos: a proporção de analfabetos absolutos teve recuo de sete pontos percentuais, evoluindo dos $13 \%$ em 2002 para $6 \%$ em 2011. (RIBEIRO et al, 2015)

Os indicadores de escolaridade da população adulta também evidenciam progresso lento, mantendo larga distância dos direitos assegurados em lei: o número médio de anos de estudos dos brasileiros com mais de 25 anos de idade evoluiu de 6,4 em 2004 para 7,7 em 2013, mantendo-se as profundas desigualdades entre os grupos de renda, idade, raça, domicílio rural-urbano e região geográfica. (IBGE, 2014) 
Outro indicador que coloca em xeque as políticas em curso é a dramática redução das matrículas na EJA registradas no Censo Escolar que, somadas as de ensino fundamental e médio, minguaram de 4.985.338 em 2007 para 3.772.670 em 2013, um recuo de 24,3\% em apenas seis anos. (BRASIL, 2014)

\subsection{QUALIFICAÇÃO PROFISSIONAL DE TRABALHADORES: O CARRO-CHEFE DA POLÍTICA FEDERAL DE EJA NA SEGUNDA DÉCADA DO MILÊNIO}

Embora fosse um governo de continuidade, a primeira gestão da Presidenta Dilma Roussef, iniciada em 2011, conferiu tonalidade própria à política federal de EJA, a começar pela adoção de um novo arranjo institucional que ampliou a abrangência da Secad, trazendo para seu interior a gestão do Projovem Urbano e da Educaçáo Especial, razão pela qual foi acrescentada a palavra Inclusão ao nome da Secretaria, cuja nova sigla passou a ser Secadi. A marca distintiva de sua gestão, entretanto, foi a criaçáo em 2011 do Programa Nacional de Acesso ao Ensino Técnico e Emprego (Pronatec), justificada pela demanda por mão de obra qualificada em um momento de expansão da economia, que crescera $7,5 \%$ em 2010.

Nas gestóes anteriores da coalizão liderada pelo PT, a política de educação profissional fora orientada, principalmente, para o restabelecimento do ensino médio integrado (que havia sido suprimido em 1997), a expansão da rede federal de educação profissional e tecnológica, e o apoio aos Estados para que ampliassem e qualificassem suas escolas técnicas, medidas que se somaram ao acordo de gratuidade com as entidades do Sistema $S^{6}$, firmado com o MEC em julho de 2008. A criação do Proeja em 2006 foi o principal ponto de intersecção entre as políticas federais de educação profissional e de EJA dos anos 2000 $\mathrm{e}$, embora tivesse pequeno porte e não ocupasse lugar de destaque na agenda da política nacional, o Programa mobilizou parcela significativa dos pesquisadores e educadores da EJA, que se engajaram na docência, formulação dos currículos, formação de educadores e monitoramento. Foi nessa ambiência que a Lei n. 11.741 de 2008 alterou o capítulo 
da LDBEN sobre Educação Profissional e Tecnológica e modificou o Art. 37, para nele inserir um parágrafo estabelecendo que a EJA deva articular-se preferencialmente à educação profissional.

Segundo Ribeiro (2014, p. 19), a Lei n. 12.513/2011 que criou o Pronatec teve origem no Legislativo, mas foi abraçada pelo Executivo, que investiu no Programa $\mathrm{R} \$ 14$ bilhóes - oriundos dos Ministérios da Educação e do Trabalho, do Fundo de Amparo ao Trabalhador (FAT) e do Banco Nacional do Desenvolvimento Econômico e Social (BNDES) - para perseguir a meta de matricular oito milhóes de pessoas no triênio 2012-2014. O Pronatec tem diversas frentes, e algumas das iniciativas colocadas sob sua abrangência existiam previamente, como a ampliação da rede de escolas técnicas federais e o subprograma Brasil Profissionalizado, de apoio às redes estaduais para expansão e melhoria do ensino técnico. A principal novidade introduzida em 2011 foi a bolsa-formação, que corresponde ao financiamento pelo governo federal das agências de formação profissional (escolas técnicas públicas e privadas, e serviços de formação profissional) para a oferta de cursos gratuitos de formação técnica (com carga horária mínima de 800 horas) concomitantes ou subsequentes ao ensino médio (inclusive na modalidade EJA), e cursos com carga horária mínima de 160 horas de qualificação profissional inicial ou continuada de trabalhadores (preferencialmente os beneficiários do seguro-desemprego e outros programas sociais), independentemente do nível de escolaridade. Segundo Franzoi e Costa (2013), 69\% das vagas oferecidas pelo Pronatec em 2012 eram de cursos de formação inicial e continuada, e apenas $31 \%$ delas eram de cursos técnicos que asseguravam também a elevação da escolaridade em nível médio, proporção similar àquela projetada para o ano seguinte.

O Pronatec vem sendo criticado por parte dos pesquisadores e educadores do campo por seu viés privatizante - a transferência de significativo montante de recursos públicos ao Sistema $S$ e outras instituiçóes privadas -, e pela oferta de cursos de curta duração voltados à qualificação pontual para o posto de trabalho, de modo desarticulado à educação básica, estratégia que rompe com a promissora perspectiva de educação integrada ensaiada em outros programas criados na gestão do Presidente Lula, como o Projovem e, principalmente, o Proeja. ${ }^{7}$ Embora pouco mencionado na literatura, um aspecto do Pronatec que merece 
atenção é a ausência de mecanismos de gestão democrática, e de instrumentos de monitoramento e avaliação de seus resultados.

A ênfase na qualificação profissional da mão de obra marca também a abordagem conferida à EJA no segundo Plano Nacional de Educação (PNE), finalmente consignado na Lei n. 13.005/2014 após longos debates no Congresso. $\mathrm{O}$ documento não adota o conceito de aprendizagem ao longo da vida, mas faz menção ao objetivo de superação do analfabetismo e menciona os jovens e adultos nas metas de universalização da educação básica e inclusão escolar das pessoas com deficiência. Duas das 20 metas do Plano referem-se especificamente à EJA: a meta nove propóe "[...] elevar a taxa de alfabetização da população com 15 anos ou mais para 93,5\% até 2015 e, até o final da vigência deste PNE, erradicar o analfabetismo absoluto e reduzir em 50\% a taxa de analfabetismo funcional [...]"; e a meta 10 "[...] oferecer, no mínimo, 25\% das matrículas de EJA, nos ensinos fundamental e médio, na forma integrada à educação profissional [...]"; desdobrando-se cada uma delas em desafiadoras estratégias de políticas.

\section{BALANÇO E PERSPECTIVAS}

Um balanço das transformaçóes da EJA no Brasil nos primeiros lustros do milênio evidencia ao menos quatro linhas de força. A primeira é o alargamento da declaração de direitos dos jovens e adultos, que passa a abranger não só a alfabetização e o ensino elementar, mas também o ensino médio e profissional, inclusive das pessoas privadas de liberdade, o que deixa amplo espaço para o exercício da advocacia para diminuir a distância que separa as leis das políticas que garantem os direitos aos cidadáos.

A segunda característica do período foi a institucionalização da EJA no arcabouço das políticas públicas de educação básica, com base na qual o ativismo em torno de numerosos programas deu margem à experimentação de várias estratégias que, se tiveram resultados pouco expressivos que colocaram a EJA na berlinda, também proporcionaram ricas aprendizagens, a partir das quais as políticas públicas podem ser reorientadas. 
A terceira característica aponta para o difícil desafio colocado para as sociedades em geral em implantar uma cultura de direitos educativos, em particular do campo da Educação ao Longo da Vida, em que açóes efetivas permitam a sua plena realização, pressionando para superar as insuficientes políticas educacionais, ao mesmo tempo estimulando a participação social por transformar demandas e direitos educativos em compromissos efetivos.

O quarto traço, para o qual convergem as agendas internacional e nacional recentes de políticas educativas, é o predomínio de uma leitura instrumental do que seja a aprendizagem continuada ao longo da vida que, visando à competitividade econômica, busca atender (inclusive mediante estratégias privatistas) exigências de qualificação para o mercado de trabalho, em detrimento da formação integral dos sujeitos, e sem compromisso com a universalidade do direito à aprendizagem. $\mathrm{O}$ enfrentamento desta "onda" enseja o fortalecimento do debate de ideias e da capacidade de articulação política da sociedade civil para incidir nos fóruns nacionais e internacionais.

\section{REFERÊNCIAS}

AFONSO, A. J. Reforma do Estado e políticas educacionais: entre a crise do Estado-Nação e a emergência da regulação supranacional. Educ. \& Soc., Campinas, v. 22, n. 75, p. 15-32, ago. 2001.

BARROSO, J. O Estado, a educação e a regulação das políticas públicas. Educ. \& Soc., Campinas, v. 26, n.92, p. 725-751, 2005.

BEISIEGEL, C. R. A educação de jovens e adultos analfabetos no Brasil. Alfabetização e Cidadania, São Paulo, v. 16, p. 19-27, 2003.

BRASIL. MINISTÉRIO DA EDUCAÇÃO. Censo da Educação Básica 2013. Brasília: MEC, fev. 2014.

CATELLI Jr., R. Alfabetização de jovens e adultos no Brasil: de programa em programa. In: MORTATTI, M. R.; FRADE, I. C. S. (Orgs.). Alfabetização e seus sentidos: o que sabemos, fazemos e queremos? Sáo Paulo: UNESP, 2014. p. 91-108. 
CATELLI Jr., R.; SOARES, L. F. S. O Encceja no cenário das políticas de educação de jovens e adultos no Brasil. In: CATELLI Jr.; HADDAD, S.; RIBEIRO, V.M. (Orgs.) A EJA em xeque: desafios das políticas de Educação de Jovens e Adultos no século XXI. São Paulo: Global, Ação Educativa, 2014, p. 77-158.

\section{CURY, C. R. J. Parecer CNE/CEB 11/2000 que dispóe sobre as Diretrizes} Curriculares para a Educaçáo de Jovens e Adultos. Brasília: MEC, CNE, 2000.

DI PIERRO, M. C. Notas sobre a redefinição da identidade e das políticas públicas de educação de jovens e adultos no Brasil. Educ. \& Soc., Campinas, v. 26, n. 92, p. 1115-1139, 2005.

. O impacto da inclusão da EJA no FUNDEB no Estado de São Paulo. In: CATELLI JR., R.; HADDAD, S.; RIBEIRO, V.M. (Orgs.). A EJA em xeque: desafios das políticas de Educação de Jovens e Adultos no século XXI. São Paulo: Global, Ação Educativa, 2014, p. 39-76.

FRANZOI, N. L.; COSTA, R. C. D. Proeja e Pronatec: a dança dos atores entre a formulação e a implementação de políticas governamentais. In: SIMPÓSIO BRASILEIRO DE POLÍTICA E ADMINISTRAÇÃO DA EDUCAÇÃO. XXVI, Políticas, planos e gestão da educação: democratização e qualidade social. Recife, 2013. Brasília: ANPAE, 2013, p. 1-15.

HADDAD, S. A participação da sociedade civil brasileira na educação de jovens e adultos e na CONFINTEA VI. Rev. Bras. Educ., vol. 14, n. 41, pp. 355-369, 2009.

IBGE. Sintese dos Indicadores Sociais: uma análise das condiçôes de vida da população brasileira. Rio de Janeiro: IBGE, 2014.

. Pesquisa Nacional por Amostra de Domicílio, 2012. Rio de Janeiro, IBGE, 2013

IRELAND, T. D. Educação de Jovens e Adultos como política pública no Brasil (2004-2010): os desafios da desigualdade e diversidade. Rizoma Freireano, v. 13, p. 93-110, 2012.

MACHADO, M. M.; ALVES, M. F.; OlIVEIRA, J. F. de. Construindo conhecimento em Educação de Jovens e Adultos (EJA) integrada à educação profissional - saberes coletivos de uma rede de pesquisadores. Educação, Santa Maria, v. 33, n. 3, p. 411-424, set./dez. 2008.

ONU. The millennium development goals report 2014. New York: United Nations, 2014. 
RIBEIRO, J. Pronatec diante da inclusão excludente e da privatização da formação. Textual, Porto Alegre, 2014. p. 16-21, maio 2014.

RIBEIRO, V. M.; LIMA, A. L.; BATISTA, A. A. (Orgs.). Alfabetismo e letramento no Brasil: 10 anos do Inaf. São Paulo: Autêntica, Ação Educativa, 2015 (no prelo).

SOARES, L. J. Os Fóruns de Educação de Jovens e Adultos: articular, socializar e intervir. Presença Pedagógica, Belo Horizonte, v. 9, n. 54, p. 15-21, 2003.

TORRES, C. A. Las secretas aventuras del orden: estado y educación. Buenos Aires:, Miño y Dávila, 1996.

. Political sociology of adult education. Rotterdam: Sense Publishers, 2013. [International Issues in Adult Education].

UNESCO. Conferência Internacional de Educação de Adultos (V: 1997, Hamburgo, Alemanha). Declaração de Hamburgo, Agenda para o Futuro. Brasília: SESI/UNESCO, 1999.

. Relatório Global sobre Aprendizagem e Educação de Adultos. Brasília: UNESCO, 2010a.

. Conferência Internacional de Educação de Adultos (VI: 2009, Belém, Brasil). Marco de Ação de Belém. Brasília: UNESCO/MEC, abril de 2010b.

. Relatório Global sobre Aprendizagem e Educação de Adultos. Brasília: UNESCO, 2014.

. Relatório de Monitoramento Global de Educação para Todos, 2015. Paris: UNESCO, 2015a.

. World Education Forum 2015. Incheon Declaration. Education 2030:

Towards inclusive and equitable quality education and lifelong learning for all. Paris: UNESCO, 2015b.

\section{NOTAS}

1. O artigo $3^{\circ}$. da Declaração de Hamburgo estabelece que a educação de adultos compreende: The entire body of ongoing learning processes, formal or otherwise, whereby people regarded as adults by the society to which they belong develop their abilities, enrich their knowledge, and improve their technical or professional qualifications or turn them in a new direction to meet their own needs and those of their society.

2. No original em inglês: We further commit to ensuring that all youth and adults, especially girls and women, achieve relevant and recognized functional literacy and numeracy profi- 
ciency levels and acquire life skills, and that they are provided with adult learning, education and training opportunities.

3. As diferentes dimensões desse projeto original nunca foram devidamente articuladas em razão das dificuldades de coordenaçáo entre o Ministério de Desenvolvimento Social e Combate à Fome, a Secretaria de Participaçáo Social da Presidência da República e o MEC, e também das tensóes entre o governo e seus interlocutores na sociedade civil.

4. Constituídos na transição do milênio, os Fóruns de Educação de Jovens e Adultos são articulaçóes pluri-institucionais que formam uma rede descentralizada com expressão pública, reconhecimento dos governos e capacidade de incidência nas políticas educacionais. (SOARES, 2003)

5. O desenho do Proeja prevê a oferta educativa, a assistência estudantil, a pesquisa avaliativa e a formação docente. Para reduzir a elevada evasão observada logo ao seu início, foi instituída uma bolsa mensal para assistência a uma parcela dos estudantes. Além de manter os cursos do Proeja, as unidades da rede federal de educação profissional e tecnológica foram incentivadas a oferecer cursos de pós-graduação latu sensu para formação de educadores e gestores. A pesquisa foi incentivada por um edital da Setec/MEC de 2006, que permitiu constituir nove grupos em todo o país. (MACHADO et al, 2008) Tendo enfrentado resistências no interior da rede federal, o Proeja não alcançou a meta de elevar para $10 \%$ a proporção de matrículas na EJA no sistema federal. (FRANZOI; COSTA, 2013)

6. A expressão Sistema $S$ designa o conjunto de instituiçóes mantido por contribuições sociais e geridas pelo empresariado para assistir e promover a formação profissional dos trabalhadores da indústria (Sesi, Senai), do comércio (Sesc, Senac), do transporte (Senat) e das empresas rurais (Senar).

7. Veja-se, por exemplo, a Carta de Natal, elaborada pelos participantes do II Colóquio Nacional "A Produção do Conhecimento em Educação Profissional" (Natal, RN, entre 6-9/8/2013) e apoiada como moção na 36a Reuniáo Anual da Associação Nacional de Pós-Graduação e Pesquisa em Educação (Anped), realizada em Goiânia, GO, no período de 29/9-2/10/2013.

Recebido em 20 de fevereiro de 2015.

Aprovado em 29 de maio de 2015.

DOI: http://dx.doi.org/10.1590/CC0101-32622015723758 